\title{
Security and Quality Assurance of ICT Enhanced Learners Support Services in Distance Education: National Open University Nigeria Experience
}

\section{Omoregbe O.Helen ${ }^{a}$ and Konyeha Susan ${ }^{b *}$}

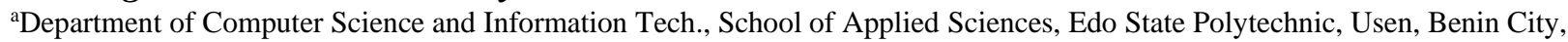
bepartment of Computer Science, University of Benin, Benin City, Edo State, Nigeria

*Email: susan.konyeha@uniben.edu

\section{Article Info}

Received 06 June 2020

Revised 16 June 2020

Accepted 17 June 2020

Available online 31 August 2020

\section{Keywords:}

Learner support, Quality Assurance, ICT, Online and Distance

Education.

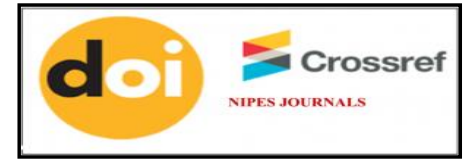

https://doi.org/10.37933/nipes/2.3.2020.3

https://nipesjournals.org.ng (c) 2020 NIPES Pub. All rights reserved.

\begin{abstract}
Learners Support Services are important parts of any Online and Distance Learning (ODL) system. Quality assurance of these services are paramount to the sustainability of ODL processes in meeting the primary learning objectives. This study focuses on quality assurance of information and communication technology tools deployed in providing supports for learners in ODL institution using National Open University of Nigeria (NOUN) as a case institution. It was conducted using survey research methodology while structured questionnaire was applied to elicit information from student who were sampled using cluster sampling techniques on the quality assurance of ICT utilization for learner support. It was statistically evident from the result of analysis that effective quality assurance processes influence the learning content design and development and provides quality learning content and services for learners' support. The outcome provides sound quality assurance blue print for quality ODL provisioning of ICT-based learner support and security of ICT infrastructures.
\end{abstract}

\section{Introduction}

The demand for university admission is growing faster than the spaces the universities are able to create [1]. One common mode of education that has helped to reduce the pressure is the Open and Distance Learning (ODL). In both developed and developing countries, the ODL is now one of the standard education channels [2]. It aims to enhance access to education to the most vulnerable, for example the poor, the illiterate, women as well as those who live in remote areas. ODL has become one of the most indispensable parts of the mainstream in educational platforms in both developed and developing countries [2]. It aims at increasing access to education to those who have difficulty in accessing it within the mainstream platform, such as finance, race, ethnicity, sex, language, disability status, and those living in remote areas [3]. According to [4], the gap between the teacher and the student by interactive methods is bridged in distance education. [3] added that Open and Distance learning refers to policies and activities enabling access to learning without or at least minimal barriers to age gaps, gender or time constraints. It was mentioned that the ODL courses consist of various course elements, including textbooks, course guides, lectures, anthologies, assignments (with or without a guidelines), television broadcasts and videotapes, radio broadcasts or audiotapes, electronic or online data, CD-ROMs, books and laboratory materials. ODL is an efficient way to access large numbers of students. One of ODL's core module is learner support. Learner assistance was recognized mainly for learner performance at ODL. 
According to [5] like everybody else, learners need help when they face the main challenge of attending a university. Student support services direct and help the students in their quest to succeed. If they learn how to work their way through these systems, success will end in an illusion, even though they plan to finish school. Based on this, the researcher wants to examine the standard of ICT infrastructure and the learner support services offered as an institution for learners at the National Open University of Nigeria (NOUN). Some research hypotheses were formulated and described as follows in order to achieve the purpose of this study:

$\mathrm{HO}_{1}$ : There is no effective quality assurance practices for learner support in NOUN.

$\mathrm{HO}_{2}$ : There is no security of ICT learner support media for NOUN student grouped by sex.

Quality assurance is the structured checking and assessment of the various aspect of a project, services, or facility to ensure standards and qualities are met [6]. Most education institutions in developing nations especially in Africa are duplicating the quality assurance structures of developed nations rather than developing their own system for delivering effective higher education [7]; [8]; [9]. [10], suggests a realist design of quality assurance process needs to reflect the predominant quality issues that it seeks to resolve. It will call for continuous balancing of the quality assurance interests in order to represent rising quality issues in higher education.

The National Open University of Nigeria (NOUN), an ODL Institution uses various Information and Communication Technologies (ICTs) to connect with their students and give them the chance to learn through different advanced technologies. The use of ICT in ODL enhances learner support systems [11]. The NOUN Quality Assurance (QA) Unit was established in August 2014 with a primary focus to promote their philosophy of quality by relentless enhancement of institutional practices and the administrative conveyance. Also the unit was charged with the responsibilities of providing training and assistance to staff on quality assurance in all sections of the university; creating awareness about quality; and preparing other units for quality review activities with a view to developing and maintaining a culture of quality enhancement in teaching-learning, research, and community engagement [12]. The Unit's overall objective is to embed a robust quality management system that promotes a culture of quality through continuous improvement of institutional practices. By developing an institutional quality assurance system, the National Open University of Nigeria, through its quality assurance unit, seeks to ensure high quality standards of its provisions and graduates by monitoring, maintaining, and improving institutional practices to meet with the standards and guidelines it has set for itself in line with national and international benchmarks for Open and Distance Learning systems [13].

\subsection{Quality Assurance in Learner Support Areas}

The Commonwealth of Learning Model (COL) for assessing the quality for distance higher education was among the leading models that has been adopted by some distance learning institutions, especially those operating in Commonwealth countries [14]. The COL's quality assurance model was equipped to conduct a summative self-assessment for quality enhancement, and track constant cycles of learning and development. [14] further claimed that, regardless of the type and management of these programs, support for learners must serve two roles - tuition and advice. Tuition services refer to a variety of activities that facilitate academic help, such as explaining to the learners a concept or guidance, discussing problems with the learners, and giving the learners feedback. Counseling programs deal with psychological and emotional support such as providing information and guidance to the learners and taking steps to help the learners conduct a summative self-evaluation for quality improvement, and monitor the processes of continuous learning and ongoing improvement. Quality learner support includes: (a) Providing help to learners across a variety of outlets, with focus on the use of suitable ICTs (b). Choosing and preparing teachers to change their functions from teachers to learning facilitators (c).Tutors give learners timely information on their assignments (d). Administrative, academic and technical personnel 
promote learner progress (e) Mechanisms exist to track and assist learners during their study period (f) Academic and social peer participation opportunities are offered, vertically with tutors and horizontally with peers (g) Measures are in place for reviews and monitoring of learner support programs and (h) Institutional structures have been developed to promote the productive advancement of students from one level of education to the next higher level and to full time employment (i) These requirements represent the fundamental elements in providing quality support to learners in distance learning.

\subsection{Quality Assurance Security of ODL}

Security is of utmost importance when securing facilities from hackers. Attacker exploits weakness and protection flaw to hack the system. Noticeable security vulnerabilities are lack of proper server hardening, incomplete network boundary security tests, application / service software deficiencies or bugs, unsafe design and coding of host applications (OS, device), poor passwords, and social engineering. Lack of operational control system / service / data protection must be protected by securing critical network, device and application / service domains resources [15].

\subsection{Quality Assurance Security Vulnerabilities Countermeasures}

[16] identifies certain security risk mitigation parameters within ODL. Authentication, access control, availability, confidentiality, honesty and non-repudiation are several countermeasures. Violation of each of the criteria leads to security breaches. All of these safety parameters are enforced along with the ICT infrastructure security policy being used in ODL. Many of the policies to be developed and enforced for the smooth running of ICT infrastructure in ODL are Network Security Policy, Host / Server Security Policy, Application Technology Security Policy, Database Security Policy and Content Management Policy (including Web Server Logging, Backup, and Password Protection).

\subsection{Factors that Promote Quality in ICT-based Education}

According to [17], factors that promote quality web-supported learning are:

i. Institutional factors - which includes; technology plan, infrastructure / adequate resources for online learning availability, student advice and consultation, institutional evaluation of programme effectiveness and coherent organizational change.

ii. Technology factors include; appropriate use of technology; reliability/robustness accessibility all round the clock (24/7); technological support available for lecturers and students; system training available for lecturers and students; and accurate management of student records/data.

iii. lecturer factors include; interaction with students/facilitation of online learning; frequent and constructive feedback to students; professional training in education, regular evaluation of lecturer competence; academic background/qualifications.

iv. Student factors consist of communication with fellow students, time management/time on task, learner control over time, place, pace of learning, expect efficiency and effectiveness, employ critical thinking strategies, motivation/commitment/self-esteem, improve students' problem-solving abilities, return on investment - customer satisfaction - cost/benefit

v. Instructional design factors include; co-operative/group learning/team work/reciprocity/collaboration; student engagement in higher cognitive levels/knowledge construction/challenges/complex thinking skills, rich learning resources/sound learning materials, interactivity/active learning/learning activities, design standards/guidelines/minimum requirements, routine review and evaluation of courses/products, enhanced student motivation/responsibility for own learning, 
manageable segments/modular/chunking, inclusivity: social, cultural, gender, disabilities, purposeful use of learning media, appropriate use of images, graphics.

vi. Pedagogical factors include; learning outcomes/objectives are clearly stated communicate high expectations, respect diverse talents and learning styles/equity for all, optimal assessment strategies/authentic tasks clearly stated expectations re: level of participation, assignments etc., provide time for students' self-reflection, provide a nonthreatening, comfortable environment, students instructed in proper research methodology, relevance and accuracy of content, research and continuous improvement, educationally significant goals, and programme is adaptable, sustainable and scalable

These factors and practices together help promote quality web-supporting experiences. But without security of all supporting processes and infrastructures acting as a layer interfacing/between each factor, the resilience usage, reliability and confidence by the stockholders of the web-based learning system will be compromised. Therefore, we advocate that an adaptive and robust security factor should be initiated (the red thick square box) as depict in Figure 1.

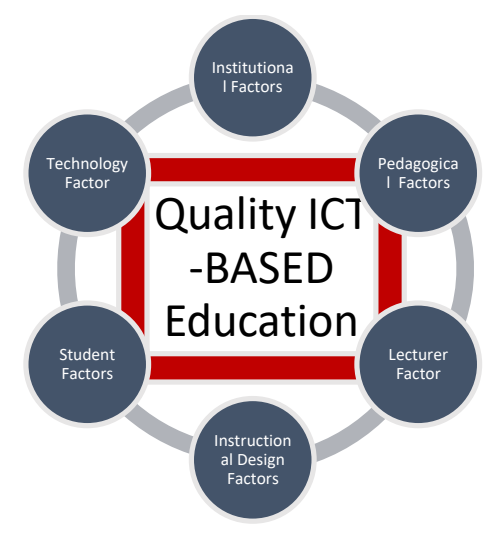

Figure 1: Factors that promote Quality in Web-based learning

The security factors address possible vulnerabilities that might compromise the overall quality of the web base education towards provide the desired learner support and meeting the expected learning goals.

\section{Methodology}

In this study, the case study research method developed by [18] has been employed in an attempt to understand social phenomena. This method of research also resonates with the world-view of constructivists. The implementation of case study analysis can be in the form of a single or multiple case studies, according to [19], [20]. This research will examine and evaluate the university-level QA programs in NOUN in order to gain insight and a collective understanding of how distance learning institutions establish and execute QA programs, especially in the area of learning infrastructure protection and support for learners. This aims to show the main features of the QA programmes employed by an institution of interest. The case study helps the researcher to understand how participants in QA programs make sense of situations or events and how these meanings are interpreted by "researcher as an instrument".

\subsection{Population, sample size and sampling techniques}

The work dealt with the student population of different NOUN study centers programmes. For this research three (3) study centers were sampled. They are the study center of Benin City in Edo State, 
study center Asaba and the community study center, both in Delta State. A cluster sampling technique has been employed to sample 242 NOUN study center respondents (students). In cluster sampling, all or some of the units within each cluster were chosen randomly to make up the sample and each cluster was a miniature of the sampled population. The sample population should be heterogeneous, according to [21], and the study considered Tight's views.

\subsection{Research Design and Data Collection}

The overall research strategy or project, is a research concept. It is the general blueprint for data collection, calculation and analysis, with the ultimate goal of solving the research problem [22]. This ensures data is validly obtained by fair and cost-effective procedures. Based on the above definition and the research goals, this study used collection of both quantitative and qualitative data to answer the research questions. Qualitative data were collected using guided questions with specific focus groups selected for purpose. Easy or uncontrolled observation has also been used, as it is the most common exploratory technique for data collection. Structured questionnaires were administered to three hundred (300) students. The questionnaire instrument was used as it was preferred to face-to - face interviews and reached a large number of respondents by enabling them to offer uninfluenced details. The questionnaires included both close-ended and open-ended questions allowing additional details to be collected from the respondents. Quantitative data was obtained from several publications, such as books, newsletters, reports, magazine, newspapers, websites and relevant literature, in order to investigate the influence of ICTs in promoting distance learning. Our data analysis was done using SPSS, a computer software. The data collection by questionnaires has been used effectively to quantitatively control variables in numerical terms.

\section{Results and Discussion}

The descriptive and inferential statistical approaches for data analysis of the responses elicited from the respondent was used for data analysis to handle the responses of students. These students were chosen at random. The analysis of the responses to questions posed under the quality assurance framework is presented here. The following tables in this section provide an analysis of the results of the data from students collected for this study. Every section of the questionnaire is discussed in detail. Table 1 describes the personal information of the 242 students from NOUN study centers.

Table 1: Descriptive Statistics of the respondents

\begin{tabular}{|l|l|l|l|}
\hline Variable & Options & Frequency & $\%$ \\
\hline \multirow{4}{*}{ Study centre } & Edo & 111 & 45.87 \\
\cline { 2 - 4 } & Asaba & 92 & 38.02 \\
\cline { 2 - 4 } & Community & 39 & 16.12 \\
\hline \multirow{3}{*}{ Type of programme } & Male & 143 & 59.09 \\
\cline { 2 - 4 } & Female & 99 & 40.91 \\
\hline \multirow{5}{*}{ Age Range } & PG & 183 & 75.62 \\
\cline { 2 - 4 } & Undergraduate & 59 & 24.38 \\
\hline & $17-20$ years & 56 & 23.14 \\
\cline { 2 - 4 } & $21-30$ years & 64 & 26.45 \\
\cline { 2 - 4 } & $31-40$ years & 79 & 32.64 \\
\cline { 2 - 4 } & $41-50$ years & 26 & 10.74 \\
\cline { 2 - 4 } & Above 50 years & 17 & 7.02 \\
\hline
\end{tabular}

Source: Field report (2019) 
Omoregbe, O. H. and Konyeha, S. / NIPES Journal of Science and Technology Research

2(3) 2020 pp. 304-313

Table 2: Summary of responses on student registration process on percentage

\begin{tabular}{|l|l|l|l|l|l|l|}
\hline Learner Support - Student Registration Process & A & $\%$ & U & $\%$ & D & $\%$ \\
\hline The process of registration is efficient. & 145 & 59.92 & 63 & 26.03 & 34 & 14.05 \\
\hline All modules are provided on registration. & 167 & 69.01 & 29 & 11.98 & 46 & 19.01 \\
\hline The registration forms are easy to fill. & 182 & 75.21 & 27 & 11.16 & 33 & 13.64 \\
\hline $\begin{array}{l}\text { Students' difficulties and challenges on course registration are attended to } \\
\text { promptly. }\end{array}$ & 171 & 70.66 & 56 & 23.14 & 15 & 6.20 \\
\hline Registration documents are verified by the Administration Officer. & 159 & 65.70 & 43 & 17.77 & 40 & 16.53 \\
\hline Library registration is carried out during the registration period. & 97 & 40.08 & 54 & 22.31 & 91 & 37.60 \\
\hline
\end{tabular}

Source: Fieldwork, (2019)

\section{Learner Support - Student Registration Process}

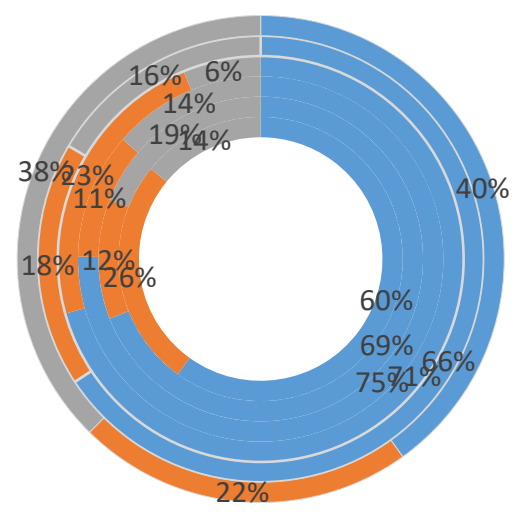

A

$\square$ U

$\square$

Figure 2: Percentage on Student Registration Process

In Figure 2, sixty (60) percent agree that the process of registration is effective, fourteen (14) percent disagree while twenty-six (26) percent are undecided. Sixty-nine (69) percent agree that all modules are made available upon registration, whereas nineteen (19) percent disagree and twelve (12) percent are undecided. Seventy (75) percent agree that registration forms can be easily filled out while fourteen (14) percent disagree and (11) percent remain undecided. Likewise, seventy-one (71) percent accept that students, experiencing difficulties and challenges during enrollment are attended to promptly, while six (6) percent disagree and twenty-three (23) percent are not sure. Sixty-six (66) percent of respondents agree that the Administration Officer verifies the registration documents while sixteen (16) percent disagrees and eighteen (18) percent disagrees. Forty (40) percent respondents agree that Library registration is conducted during the period of registration while thirty-eight (38) percent disagree and twenty-two (22) percent are not certain. The percentage of respondents who agree to the student enrollment method is also higher than the percentage of those who disagree

Table 3 Summary of responses on student programme processes on percentage

\begin{tabular}{|l|l|l|l|l|l|l|}
\hline Learner Support - Programme Processes & A & $\%$ & U & $\%$ & D & $\%$ \\
\hline $\begin{array}{l}\text { Tutorials are supervised by the appointed officer/Regional Programme } \\
\text { Coordinators. }\end{array}$ & 170 & 70.25 & 17 & 7.02 & 55 & 22.73 \\
\hline The student advisor monitors tutorials. & 137 & 56.61 & 17 & 7.02 & 88 & 36.36 \\
\hline The quality assurance officer monitors quality of tutorials. & 197 & 81.40 & 18 & 7.44 & 27 & 11.16 \\
\hline I make regular tutor evaluations during tutorials. & 184 & 76.03 & 28 & 11.57 & 30 & 12.40 \\
\hline
\end{tabular}


Omoregbe, O. H. and Konyeha, S. / NIPES Journal of Science and Technology Research 2(3) 2020 pp. 304-313

\begin{tabular}{|l|l|l|l|l|l|l|}
\hline Marking is thorough. & 172 & 71.07 & 11 & 4.55 & 59 & 24.38 \\
\hline Comments in marking are helpful. & 161 & 66.53 & 32 & 13.22 & 49 & 20.25 \\
\hline Marking is moderated by the Regional Programme Coordinator. & 130 & 53.72 & 9 & 3.72 & 103 & 42.56 \\
\hline I sign for handing in assignments. & 190 & 78.51 & 20 & 8.26 & 32 & 13.22 \\
\hline I sign when collecting marked assignments. & 161 & 66.53 & 14 & 5.79 & 67 & 27.69 \\
\hline Feedback on my marked assignments is given during tutorials. & 198 & 81.82 & 33 & 13.64 & 11 & 4.55 \\
\hline I can obtain all the learning materials I need in the e-library. & 144 & 59.50 & 21 & 8.68 & 77 & 31.82 \\
\hline I can easily access internet information from the e-library. & 187 & 77.27 & 30 & 12.40 & 25 & 10.33 \\
\hline $\begin{array}{l}\text { There is an officer in charge to attend to all my programme challenges } \\
\text { professionally. }\end{array}$ & 178 & 73.55 & 33 & 13.64 & 31 & 12.81 \\
\hline $\begin{array}{l}\text { There is regular communication about the programme issues between } \\
\text { myself and the officer in charge. }\end{array}$ & 185 & 76.45 & 18 & 7.44 & 39 & 16.12 \\
\hline $\begin{array}{l}\text { There is regular communication between myself and } \\
\text { The Students' Representative. }\end{array}$ & 156 & 64.46 & 32 & 13.22 & 54 & 22.31 \\
\hline
\end{tabular}

Source: Fieldwork, (2019).

In Figure 3, seventy (70) percent of the respondents agree that tutorials are supervised by the appointed officer / Regional Programme Coordinators while twenty-three (23) percent disagree and seven (7) percent are not decided. Fifty-one (51) percent agree that the student advisor monitors tutorials, thirty-six (36) percent disagree and seven (7) percent were undecided. Eighty-one (81) percent agree that the quality assurance officer monitors quality of tutorials, seven (7) percent were undecided and eleven (11) percent disagree. Seventy-six (76) percent agreed that they make regular tutor evaluations during tutorials, twelve (12) percent were undecided while another twelve (12) percent disagree that they make regular tutor evaluation during tutorials.

Seventy-one (71) percent agree, five (5) percent are undecided and twenty-four (24) percent disagree respectively that marking is thorough. Fifty-four (54) percent of the respondents agree that marking is moderated by the Regional Programme Coordinator, forty-three (43) percent disagree and four (4) percent were undecided.

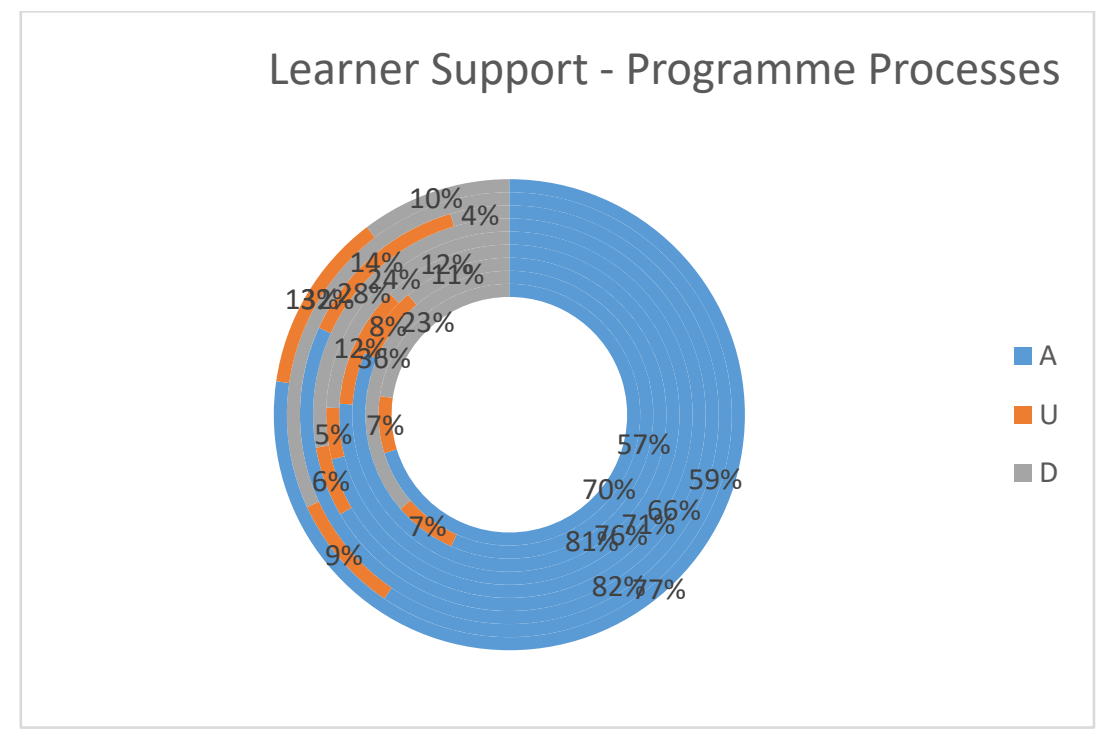

Figure 3: Percentage on Programme Process

Seventy-nine (79) percent of the respondents agree that they sign for handling assignment, eight (8) percent were undecided and thirteen (13) percent disagree. Sixty (60) percent of the respondents 
agreed that they can obtain all the learning materials they need in the e-library, nine (9) percent were undecided and thirty-two (32) percent disagreed. Seventy-four (74) percent of the respondents agree that there is an officer in charge to attend to all their programme challenges professionally, fourteen (14) percent were undecided and thirteen (13) percent disagreed. Seventy-five (75) percent agree that there is regular communication about the programme issues between students and the officer in charge while seven (7) percent were indecisive and sixteen (16) percent disagreed. Hence, the percentage of respondents who agree to the program process is more than the percentage of those who disagree. This is in line with the [23] review of 150 distance learning programs in Sub-Saharan Africa and he concluded that traditional paper-based distance learning methods remain more reliable, sustainable and widely used than online and web-based learning methods.

Table 4 Summary of students' responses on question on security

\begin{tabular}{|c|c|c|c|c|c|c|}
\hline Question on Security & A & $\%$ & $\mathrm{U}$ & $\%$ & $\mathrm{D}$ & $\%$ \\
\hline $\begin{array}{l}\text { During orientation, security workshop on how to protect oneself } \\
\text { online was organized }\end{array}$ & 168 & 69 & 36 & 15 & 38 & 16 \\
\hline There is a privacy and security policy regarding personal data & 155 & 64 & 34 & 14 & 53 & 22 \\
\hline Clear examination procedures are put in place & 189 & 78 & 39 & 16 & 14 & 6 \\
\hline $\begin{array}{l}\text { The university has an intellectual property unit where plagiarism is } \\
\text { reviewed in research works }\end{array}$ & 144 & 60 & 36 & 15 & 62 & 26 \\
\hline When students, sign into the online test, identity is authenticated. & 196 & 81 & 33 & 14 & 13 & 5 \\
\hline Effective measures are in place to detect impersonation & 143 & 59 & 34 & 14 & 65 & 27 \\
\hline Students have access to guidelines on examinations & 158 & 65 & 41 & 17 & 43 & 18 \\
\hline Exam questions are secured by various means to enhance the integrity & 153 & 63 & 49 & 20 & 40 & 17 \\
\hline Student identity is regularly checked using biometrics & 185 & 76 & 39 & 16 & 18 & 7 \\
\hline $\begin{array}{l}\text { Students know what materials, equipment and tools they can use } \\
\text { during examination }\end{array}$ & 162 & 67 & 30 & 12 & 50 & 21 \\
\hline
\end{tabular}

Source: Field work, (2019

\section{Question on Security}

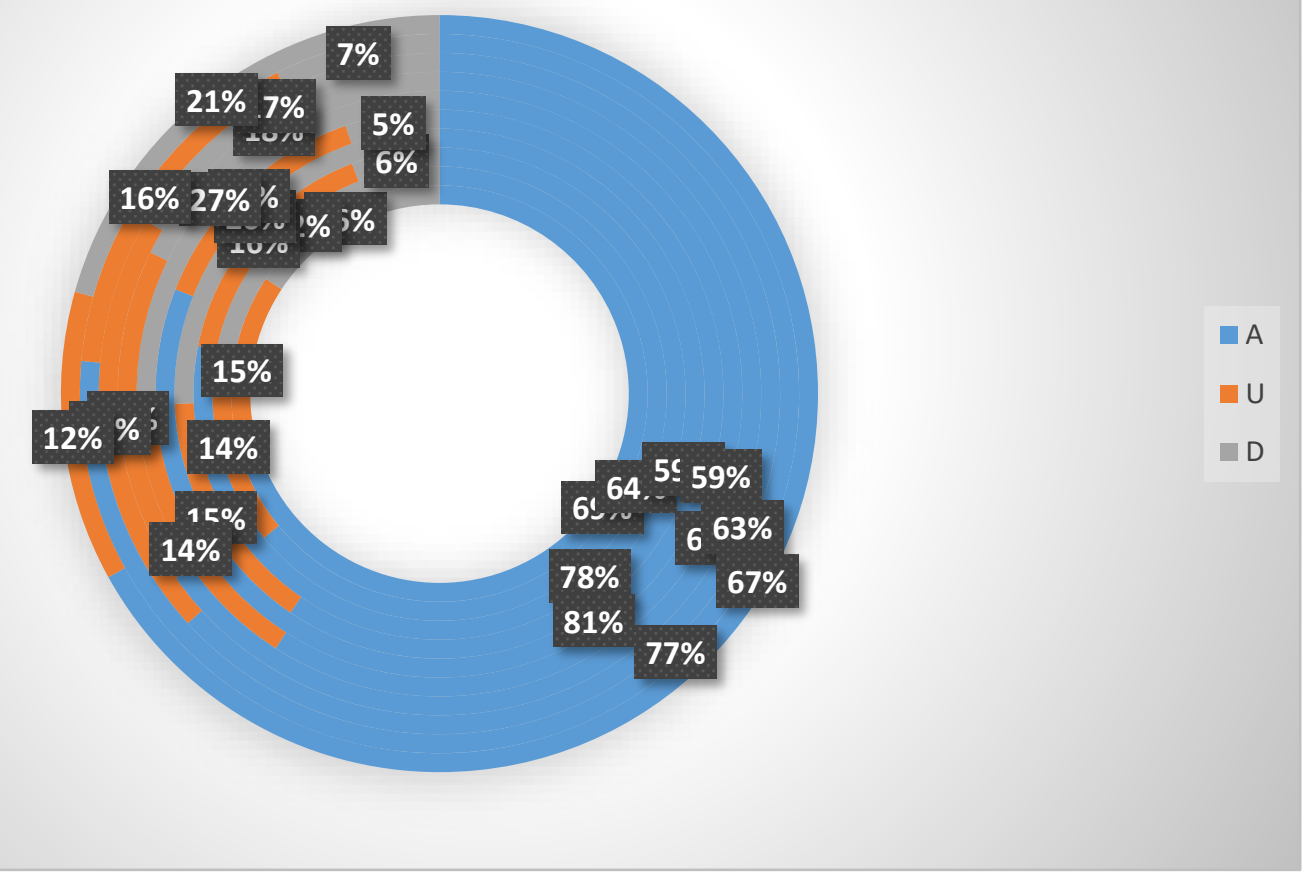

Figure 4: Percentage on security 
In Figure 4, sixty-nine (69) percent of the respondent agreed that security workshop on how to protect students online was organized during orientation while fifteen (15) percent were undecided and sixteen (16) percent disagreed. Sixty-four (64) percent agreed that there is a privacy and security policy regarding personal data and twenty-two (22) percent disagreed. Fourteen (14) percent were undecided. Seventy-eight (78) percent agreed that there are clear examination procedures in place and six (6) percent disagreed while sixteen (16) percent were undecided. Sixty (60) percent agreed that the university has an intellectual property unit, where plagiarism in research works is reviewed while fifteen (15) percent were undecided and twenty-six (26) percent disagreed. Eighty-one (81) percent of respondents agreed that when students, sign into the online test, identity is authenticated. and five (5) percent disagreed while fourteen (14) percent were undecided. Fifty-nine (59) percent agreed that effective measures are in place to detect impersonation and twenty-seven (27) percent disagreed while fourteen (14) percent were undecided. Sixty-five (65) percent of respondents agreed that sstudents have access to guidelines on examinations, while eighteen (18) percent disagree, seventeen (17) percent are undecided. Sixty-three (63) percent of respondents agreed that examination questions are secured by various means to enhance the integrity and seventeen (17) percent disagreed while twenty (20) percent were undecided. Seventy-six (76) percent of respondents agreed that student identity is regularly checked using biometrics, sixteen (16) percent were undecided and seven (7) percent disagreed. Sixty-seven (67) percent of respondents agreed that students know what materials, equipment and tools they can use during examination and twenty-one (21) percent disagreed while twelve (12) percent were undecided. Therefore, the percentage of respondents that agree to security of both student personal information and learning and examination processes were more than the percentage that disagree. This agrees with [16] that device / service / data protection is to be maintained by protecting critical resources in network, system, and application / service domains. Some of the parameters of security are authentication, access control, availability, confidentiality, credibility and non-repudiation Infringement of each of the parameters leads to a security breach. Both these protection requirements to be followed, along with the ICT infrastructure security framework to be used in open distance learning.

\subsection{Hypothesis Testing}

To test the stated hypothesis, the cross tabulation or chi-square $\left(\mathrm{X}^{2}\right)$ statistics was used. The findings of the study are illustrated in Table 5.

Table 5: Cross tabulation or chi-square $\left(\mathrm{X}^{2}\right)$ from the stated hypothesis for the findings.

\begin{tabular}{|c|c|c|c|c|c|c|c|}
\hline Learner Support - Programme Processes & & A & $\mathrm{U}$ & $\mathrm{D}$ & & $X^{2}$ & p-val \\
\hline \multirow{2}{*}{$\begin{array}{l}\text { Tutorials are supervised by the appointed officer/Regional } \\
\text { Programme Coordinators. }\end{array}$} & M & 102 & 11 & 30 & 143 & \multirow[b]{2}{*}{0.75} & \multirow[b]{2}{*}{0.39} \\
\hline & $\mathrm{F}$ & 68 & 6 & 25 & 99 & & \\
\hline \multirow[b]{2}{*}{ The student advisor monitors tutorials. } & M & 78 & 9 & 56 & 143 & \multirow[b]{2}{*}{1.28} & \multirow[b]{2}{*}{0.26} \\
\hline & $\mathrm{F}$ & 59 & 8 & 32 & 99 & & \\
\hline \multirow[b]{2}{*}{ The quality assurance officer monitors quality of tutorials. } & M & 122 & 11 & 10 & 143 & \multirow[b]{2}{*}{6.12} & \multirow[b]{2}{*}{$* * 0.01$} \\
\hline & $\mathrm{F}$ & 75 & 7 & 17 & 99 & & \\
\hline \multirow[b]{2}{*}{ I make regular tutor evaluations during tutorials. } & M & 102 & 22 & 19 & 143 & \multirow[b]{2}{*}{5.64} & \multirow[b]{2}{*}{$* * 0.02$} \\
\hline & $\mathrm{F}$ & 82 & 6 & 11 & 99 & & \\
\hline \multirow[b]{2}{*}{ I sign (LOG IN) for handing assignments. } & $\mathrm{M}$ & 99 & 17 & 25 & 141 & \multirow[b]{2}{*}{16.78} & \multirow[b]{2}{*}{$* * 0.00$} \\
\hline & $\mathrm{F}$ & 91 & 3 & 5 & 99 & & \\
\hline \multirow[b]{2}{*}{ I can obtain all the learning materials I need in the e-library. } & M & 96 & 12 & 35 & 143 & \multirow[b]{2}{*}{9.37} & \multirow[b]{2}{*}{$* * 0.00$} \\
\hline & $\mathrm{F}$ & 48 & 9 & 42 & 99 & & \\
\hline \multirow[b]{2}{*}{ I can easily access internet information from the e-library. } & M & 102 & 22 & 19 & 143 & \multirow[b]{2}{*}{7.07} & \multirow[b]{2}{*}{$* * 0.01$} \\
\hline & $\mathrm{F}$ & 85 & 8 & 6 & 99 & & \\
\hline \multirow{2}{*}{$\begin{array}{l}\text { There is an officer in charge to attend to all my programme } \\
\text { challenges professionally. }\end{array}$} & M & 98 & 23 & 22 & 143 & \multirow[b]{2}{*}{4.54} & \multirow[b]{2}{*}{$* * 0.03$} \\
\hline & $\mathrm{F}$ & 80 & 10 & 9 & 99 & & \\
\hline
\end{tabular}


** indicates statistically significant at 0.05 level.

As shown in Table 5, most of the results show significance at the level of 0.05 (95 percent). The decision was to accept the null hypothesis if the p-value is equal to or less than 0.05 .

The designated officer / regional program coordinators supervise all shows of substantial acceptance for tutorials and the student advisor tracks tutorials. All results show significance except for tutorials monitoring and supervision by the designated officer / Regional Programme Coordinators and the student advisor. It was evident from the student's responses and response data analysis that quality assurance processes are needed in any learning system to enshrine policies and standards. The results also revealed that quality assurance will encourage the creation of learning content which supports learners. This research also reflects that students agree that access to their learning materials was easy and that appropriate security measures are always maintained. We will conclude by using the fact established from the analysis:

For Hypothesis 1: The alternate hypothesis $\left(H A_{1}\right)$ is accepted. There are effective quality assurance practices for learner support in NOUN as reveals from Table 4.

For Hypothesis 2: The alternate hypothesis $\left(\mathrm{HA}_{2}\right)$ is accepted. There is security of ICT learner supports for NOUN student grouped by sex.

\section{Conclusion}

This study defined the role of quality assurance practices through policies and standards in optimizing the learning processes. It highlighted some factors which influence the educational system driven by ICT. It further explores the need for a quality education system based on ICT in order to support learners. The findings indicate that ODL institutions can implement stable and consistent methodologies while also attempting to resolve other issues related to introducing modern technology into the learning environment, robust internet service, constant power supply, proper maintenance, and efficient administration. Wherever these are available, quality learning materials will be developed and the system will provide the learner with leaner support services.

\section{References}

[1] Arikpo, I. (2008). Bridging the digital divide: the Nigerian journey so far. International Journal of Global Business, 2(1), $181-204$.

[2] Blurton, C. (2002). New Directions of ICT-Use in Education. UNESCO. Retrieved April 7, 2019, from http://www.unesco.org/education/educprog/lwf/dl/edict.pdf;

[3] Ajadi, T., Salawu, I., \& Adeoye, A. (2008). E-learning and Distance Education in Nigeria. The Turkish Online Journal of Educational Technology, 7(4), 61-70.

[4] Dhanarajan, J. (2001). Mega-Universities and Knowledge Media. London: Kogan Press.

[5] Qakisa-Makoe, K. (2005). Economics of Development. (6. edition, Ed.) New York:: WW Norton.

[6] Merrian-Wester. (2019). Quality Assurance. Retrieved from Merrian-Webster Online Dictionary: www.merriam-webster.com

[7] Anash, F., Swanzy, P., \& Nudzor, P. (2017, June 7). Balancing the focus of Quality Assurance Framworks of Higher Education Institutions in Africa: A Ghanian Context. Retrieved from Intechopen Access: www.intechopen.com

[8] Odhiambo, G. (2014). Quality Assurance forpublic higher education: centext, strategies and chanllangies inKenya. Higher Education Research and Development, 33, 978-991.

[9] Ansah, F. (2015). Conceptualizing external and internal quality assurance in higher education-Apragmatist perspective. International Journa ofAfrican Higher Education, 1, 135-152.

[10] Ansah, F. (2015). Strategic quality assurance framework in higher education context. Quality in Higher Education, 21(2), $132-150$.

[11] Anderson, M., \& Jackson, D. (2000). Computer systems for distributed and distancelearning. Journal of Computer Assisted Learning, 16, 213-228.

[12] AAOU. (2010, 10 September). Quali perce percent nt ty assurance framework. Retrieved January 17, 2011:. Retrieved August 13, 2019, from http://www.aaou.net.

[13] NOUN. (2019). Quality Assurance Unit. Retrieved September 7, 2019, from National Open university of Nigeria: www.nou.edu.ng

[14] Coomaraswamy, U., \& Clarke-Okah, W. (2009). Quality assurance toolkit for distance higher education institutions and programmes. (R. Kondapalli, \& H. Andrea, Editors) Retrieved November 17, 2019, from Common Wealth of Learning: www.hdi.handle.net/11599/105

[15] Bogue, E. (2008). Quality assurance in higher education: The evolution of systems and design ideals. . In G. H. Gaither (Ed.), Quality assurance in higher education.

[16] Murali, A., \& Rao, M. (2010). Digital library security. Journal of Computing Techniques, 3(1), 34-45.

[17] Robinson, B. (2008). Using distance education and ICT to improve access. London: Kogan Page.

[18] Stake, F. (2005). E-learning: Strategies for delivering knowledge in the digital age. New York : McGraw-Hill.

[19] Yin, R. (2003). Case study research: Design and methods. (3. ed, Ed.) Thousand Oaks CA: SAGE Publications.

[20] Yin, R. (2012). Application of case study research. Los Angeles: SAGE Publication,Inc

[21] Tight, M. (2008). Distance education: Discipline and service. Journal of Distance Education, 26(1), 81-84.

[22] Creswell, J. W. (2003). Research design: Qualitative, quantitative, and mixed methods approaches. London: Sage publications.

[23] Gulati, S. (2008). Technology-Enhanced learning in developing Nations: A review. The International Review of Research in Open and Distriuted learning, 9(1). doi:http://doi.org/10.19173/irrodl.v9i1.477 